\title{
Paving the post-covid Rhinology era with ERS!
}

One year after the global COVID19 outbreak, there is hope for the Rhinology community and for patients suffering from chronic rhinologic conditions. Not only is there the prospectus of restoring normal rhinology care delivery in 2021, but also the possibility of implementing the learnings from this pandemic in daily practice leading to even better care in the post-covid era. Thanks to major efforts of several European Rhinologic Society members in studying and publishing their experiences on disease presentation ${ }^{(1)}$, protection ${ }^{(2)}$, clinical guidance ${ }^{(3,4)}$, impact on daily rhinology practices ${ }^{(5)}$ and insight into disease recovery ${ }^{(6)}$ in Rhinology, the medical community has gained better insight into SARS-CoV-2 relate aspects of disease. The recent Rhinology publications on this historic topic have not only led to a better understanding of the pathophysiology of SARS-CoV2 induced inflammation, but also to better care of viral exacerbations in those with and without pre-existing rhinologic conditions. Viruses have always been around and contributed to exacerbations and disease progression in conditions like rhinitis, rhinosinusitis and global airways diseases. Currently ongoing trials on the impact of SARS-CoV2 infections on sensitization to inhalant allergens, on smell dysfunction, on disease initiation and best anti-viral treatment strategies will undoubtedly have a major impact on rhinology care in the future. Therefore, lots of work still has been to performed to find the answers to several very relevant clinical questions.

In addition to all research initiatives, the COVID pandemic has also speeded the process of virtual dissemination of scientific knowledge with acceptance of webinars ${ }^{(7)}$, virtual testimonials and globalization of the outreach of training efforts. Physicial meetings will however remain appreciated given the personal flavour and other moments of inspiration by direct contact.
In that context, I would propose to join forces with chairman Professor Jannis Constantinidis in making the postponed ERS bi-annual meeting in Thessaloniki, September 2021, a real success at educational level with a warmly welcomed reunion of colleagues and friends from all over the globe.

The June issue of Rhinology 2021 is very appealing for the ERS community and all readers given 3 unique systematic review papers and several high-standard research papers on novel insights into relevant topics like the definition of CRS, the pathophysiology of CRRS, novel care pathways for CRS including timely endoscopic sinus surgery, and novel treatment options for CRSwNP including biologicals. In 2021, we seem to finally move forward to an era of timely access to the right treatment for patients suffering from rhinologic conditions.

I hope you will enjoy reading the June 2021 issue of Rhinology with as much inspiration as myself!

by Peter Hellings

Leuven, Belgium

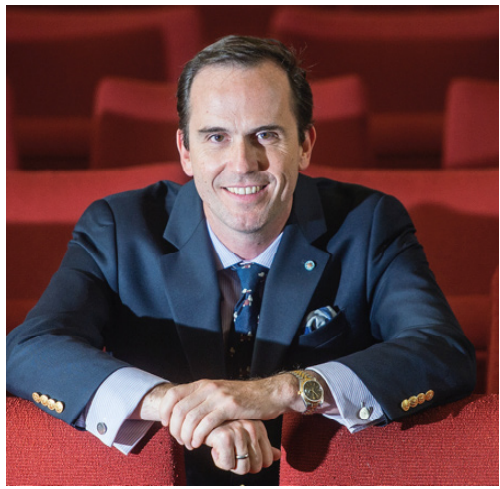

\section{References}

1. Lechner M, Chandrasekharan D, Jumani K, et al. Anosmia as a presenting symptom of SARS-CoV-2 infection in healthcare workers - A systematic review of the literature, case series, and recommendations for clinical assessment and management, Rhinology. 2020, Aug 1;58(4):394-399.

2. Van Gerven L, Hellings PW, Cox T, et al. Personal protection and delivery of rhinologic and endoscopic skull base procedures during the COVID-19 outbreak. Rhinology 2020, Jun 1;58(3):289-294.

3. Huart C, Philpott C, Konstantinidis I, et al.
Comparison of COVID-19 and common cold chemosensory dysfunction. Rhinology 2020, Dec 1;58(6):623-625.

4. Boscolo-Rizzo P, Polesel J, Spinato G, et al., Predominance of an altered sense of smell or taste among long-lasting symptoms in patients with mildly symptomatic COVID-1. Rhinology 2020, Oct 1;58(5):524-525.

5. Klimek L, Hagemann J, Alali A, et al. The toll of noninfected CRS patients to the COVID-19 pandemic.Rhinology 2020, Oct 1;58(5):522-523.

6. Speth MM, Singer-Cornelius T, Oberle M, Gengler I, Brockmeier SJ, Sedaghat AR. Time scale for resolution of olfactory dysfunction in COVID-19. Rhinology 2020, Aug 1;58(4):404-405

7. Hellings $P$, Scadding $G$, Bachert $C$, et al. EUFOREA treatment algorithm for allergic rhinitis. Rhinology 2020, Dec 1;58(6):618622. 